\title{
石油污染が海洋生物に及ぼす影響の基礎的研究一I 流出油乳化剤の植物プランクトンに対する致死濃度
}

徳田廣・新崎盛敏

(1976 年 6 月 23 日受理)

\author{
Fundamental Studies on the Influence of Oil Pollution upon \\ Marine Organisms-I. \\ Lethal Concentrations of Oil-spill Emulsifiers for \\ Some Marine Phytoplankton
}

Hiroshi TokUda*1 and Seibin ARASAKI*2

\begin{abstract}
The lethal concentrations of 84 commercially produced oil-spill emulsifiers for marine phytoplankton were determined by culture experiments. The samples of oilspill emulsifiers were collected in August of 1971 ( 54 domestic and foreign products), 1973 (12 domestic products), 1974 (14 domestic products) and 1975 (4 foreign products). Among 3 species of phytoplankton used as test organisms, Skeletonema costatum was the most sensitive, Nitzschia closterium moderately sensitive, and Chlamydomonas sp. the least sensitive to the toxicity of oil-spill emulsifiers. The toxicity of oil-spill emulsifiers was reduced year after year due to the improvements in thier components. The most recently produced oil-spill emulsifiers did not inhibit the growth of Skel. costatum at a concentration of $100 \mathrm{ppm}$; moreover, some of them allowed the growth of this alga even at a concentration of $10,000 \mathrm{ppm}$.
\end{abstract}

現代沈石油時代といわれ，石油なくして現在の文明社会の存続や発展が考克られない活ど，われわれの生 活は石油の恩恵をうけている。先進諸国に扣ける石油消費の增大によつて，油産国から消費国へ海上を経由 して運ばれる石油量は，年間莫大な量にのぼり，空船時にタンカーによつて海上投蕃された dirty ballast や tank cleaning water，あるいはその他の原因から海上に流出した石油により，すでに世界の海の大部分 は污染されている。

一方，地球上の人口は年々增加の一途を辿り，現在でもすでに食糧不足が叫ばれて㧊り，食糧生産するい はタンパク質生産の場としての海洋は，今後ますます重要性を增してくるわけである。人類の生存にとつて かけがえのない海が，石油によつて污染される結果，そこに生息する生物がどのような影響をらけるか，す てにすぐれた総説1-ら゙ が発表されているが，まだ末知な点む多く残されている。そこで筆者は，微力ながら 海洋生物におよ括す石油污染の影響の研究に着手しだ。

流出油の姏理には, 物理的方法と化学的方法に大别される 2 法が適用されており, それぞれの方法はさら

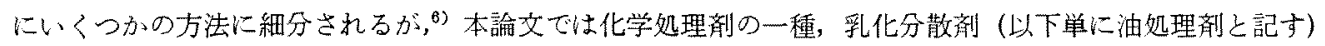
の対生物毒性の程度を知る手がかりとして，その植物プランクトンに対する致死濃度を求めてみた。

\section{材料と方法}

油処理剂は，1971 年 8 月，当時放が国で市肘されていだととんどすべての国産品および外国製品の 54 種

*1 東京大学農学部水産学科 (Dept. of Fish., Univ. of Tokyo, Tokyo, Japan).

*2 日本大学農锰医学部水産学科 (Dept. of Fish., Nihon Univ. Tokyo, Japan). 
類，1973 年 8 月および 1974 年 8 月にそれぞれ当時の市肘国産品より無作為に抽出された 12 種類と 14 種類, ざらに 1975 年 8 月に入手した外国製品 4 種類，を㙁性試験に用いた。

供試生物としては, 神奈川県三浦半島油壱湾産の海産 Chlamydomonas sp., Nitzschia closterium,なら び化海道釗路港沖産の Skeletonema costatum 走用いた。

基本培養液には岩崎に上る $\mathrm{SW} \mathrm{II}$ をを用い，これに各油処理剂を超音波処理により乳化させ，10 倍希釈列 もしくは対数的希积列を験液として調整し，験液 $50 \mathrm{ml}$ に対し，あらかじめ SWII 液中て培盖して括いた

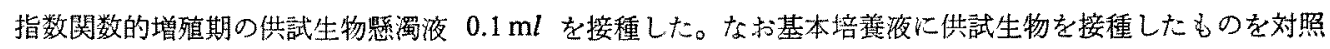
とした。

培巍条件は, 1971 年 8 月入手の試料関しては, Chlamyd. sp., では温度 $26^{\circ} \mathrm{C}$, 照度 4,000 lux, 培盖 期間 7 日間, Nitz. closterium では照度 4,000 lux, 温度は 71-1 から 71-43 までの試料では $26^{\circ} \mathrm{C}$ 71-44

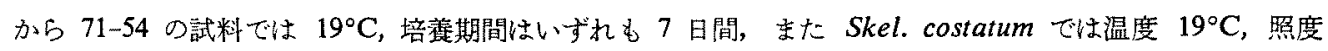
4,000 1ux, 培養期間 6 日間で行なつた。1973年 8 月以後に入手した試料に関しては，すべて Skel. costatum を供試生物とし，温度 $20^{\circ} \mathrm{C}$ ，照度 4,600 lux にて 10 日ないし 2 週間培養を行なつた。

上記のいずれの場合も培養器は恒温槽内に静置し, 下側より連続照明を施した。また培養期間中, 1 日数 回手で軽く培養器を振とうし, 内容物をかくはんした。培養終了後, 各験液中での植物プランクトンの增殖 の有無を肉眼ならびに光学䫓微鏡で確め, 油処理剤の致死漉度を求めた。

\section{結果と考察}

1971 年 8 月に入手した油処理郕の植物プランクトンに対する致死濃度は, Table 1 に示したごとくであ る。本表中で, ある濃度を示吉数字の真下に線 (太い直線, 点線もしくは破線) が引かれている試料は, そ の濃度が線の種類によつて区別された供試生物の致死濃度を示しており，また2つの濃度の中間に線が引か れている試料では，両浱度の中閒に供試生物の致死濃度があることを示している。

すな方ち，Nitz. closterium で毒性検定を行なつた 54 種類の試料については，致死濃度が $1 \mathrm{ppm}$ 末満 のもの 7 種類, $1 \mathrm{ppm} の も の 1$ 種類, $1 \mathrm{ppm}$ と $10 \mathrm{ppm}$ との中間（以下 $1 \sim 10 \mathrm{ppm}$ のごとくに記す）の

Table 1. Anti-algal spectrum of 54 oil-spill emulsifiers sampled in August 1971

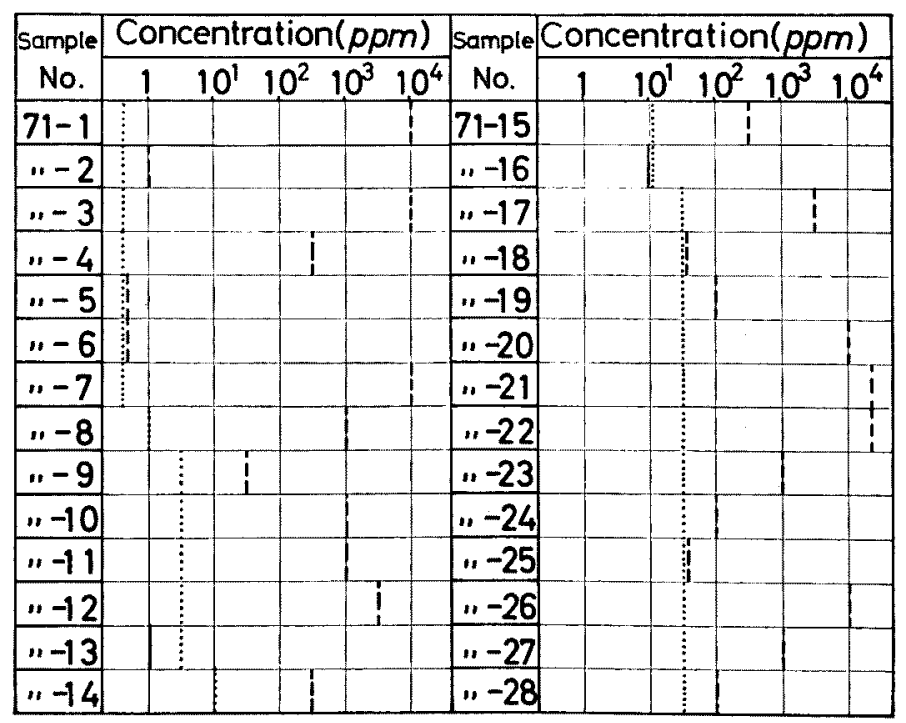

Note: ...... Nitz. closterium, ...- Chlamyd, sp., - Skel. costatum. 


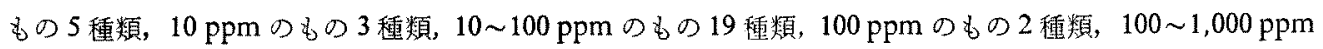
のもの 1 種類, $1,000 \mathrm{ppm}$ のの 4 種類, $1,000 \sim 10,000 \mathrm{ppm}$ のすの 1 種類, $10,000 \mathrm{ppm}$ のの 6 種類, $10,000 \mathrm{ppm}$ を越えるもの 5 種類であつた。

Chlamyd. sp. で毒性唡定觉行つた 43 種類の試料については, 致死浀度が $1 \mathrm{ppm}$ 末满のもの 2 種類, $1 \mathrm{ppm}$ のもの 1 種類, $10 \sim 100 \mathrm{ppm} の$ もの 4 種類, $100 \mathrm{ppm} の も の 4$ 種類, $100 \sim 1,000 \mathrm{ppm} の$ もの 7 種

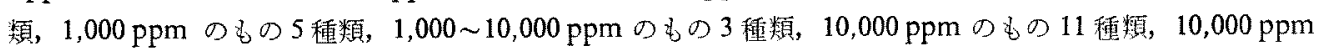
を越えるもの 6 種類であつた。

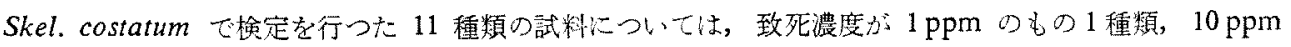
のもの 3 種類, $10 \sim 100 \mathrm{ppm}$ のも 2 種類, $100 \mathrm{ppm}$ のの 1 種煩, $1,000 \mathrm{ppm} の も の 1$ 種類, $1,000 \sim$ $10,000 \mathrm{ppm}$ のも 3 種類であつた。

以上の結果を生物種別に比較してみると，Skel. costatum 价油処理剂に対してもつとも敏感で低い耐性を 示し, Nitz. closterium 洁 Skel. costatum 上り 10 倍以上强く, Chlamyd. sp. は Nitz. closterium 上り さらに 10 倍ないし100倍強いといつてよからう。したがつて, これ以降の油処理剤の毒性試験用供試生物

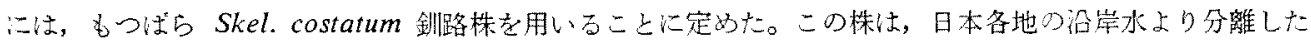
9 楼の Skel. costatum のうちで，油処理剂に対してちょうど平均的な感受性を示すものである8。

1973 年, 1974 年, 拉よび 1975 年の各 8 月に入手した試料の Skel. costatum に対する致死濃度は,

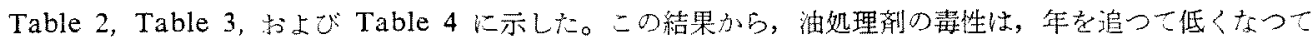
いるのが明白である。

油処理剤の組成は, 企業秘密とされているようであるが, 勧者が調查した結果を示すと, ひじょうに概括

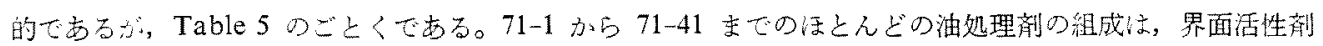
部としてエーテル型非イオン系界面活性郕, 溶郕部として石油采炭化水素, から成つて㧍り,トレーキャ二 オン号座樵事故（1967 年 3 月 18 日）の際に使用された高毒性の油処理剷”之同類の組成のもので西る。 油処理剂に上つて海水中に乳化した石油は, 種々の海洋生物, なかんずく微生物によつて变筫・分解され

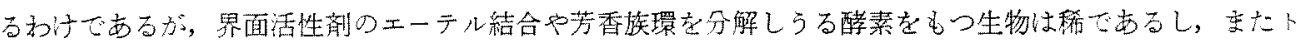

Table 1. continued

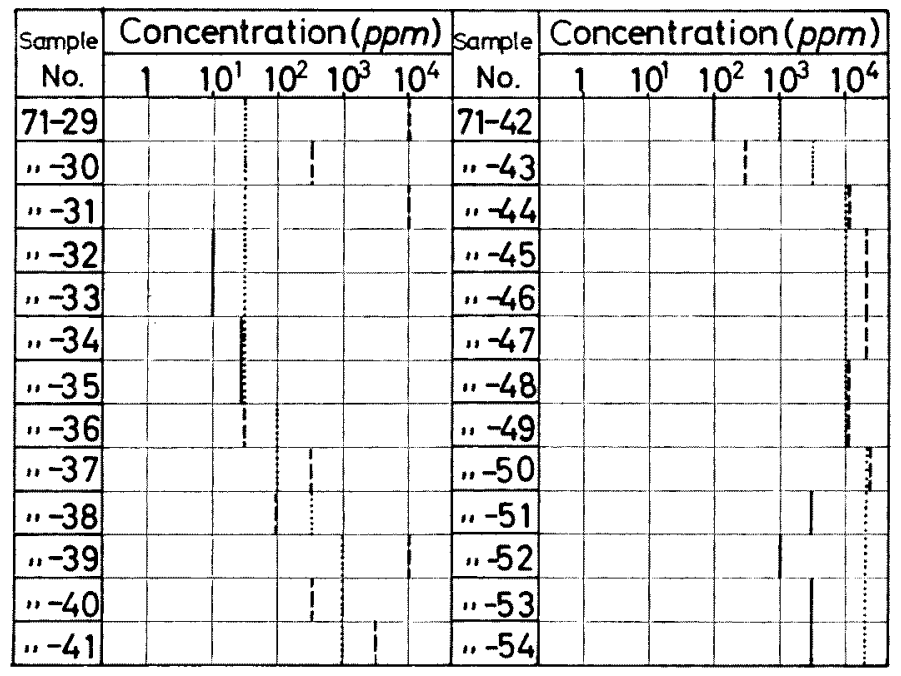


レーキャニオン号当時の油処理剂に使用されていた溶剤部には, 流出油との乳化状態を安定させるため, 芳 香族分画を多く含んだ石油系炭化水妻が好んで用いられていたので, 油処理剂は対生物毒性が高いらえ, 微 生物分解が困難であつた。このような理由から, 油処理剤散布時の実施方法によつては，2次污染の原因と なつたのである。

しかし，71-43，71-46，71-52 の試料では，界面活性剂部はエステル型非イオン䒺界面活性風に，71-52 では溶剤部も nーパラフィンに改められ，生分解を容易ならしめるとともに低毒性化が計られている。

Table 2. The growth of Skeletonema costatum on media with various concentrations of 12 domestic oil-spill emulsifiers sampled in August 1973

\begin{tabular}{cccccccccc}
\hline \multirow{2}{*}{$\begin{array}{c}\text { Sample } \\
\text { No. }\end{array}$} & \multicolumn{7}{c}{ Concentration (ppm) } \\
\cline { 2 - 10 } & 10 & 18 & 32 & 56 & 100 & 180 & 320 & 560 & 1,000 \\
\hline $73-1$ & + & + & + & + & + & + & - & - & - \\
$73-2$ & + & + & + & + & + & + & \pm & - & - \\
$73-3$ & + & + & + & + & + & + & \pm & - & - \\
$73-4$ & + & + & - & - & - & - & - & - & - \\
$73-5$ & + & + & + & + & + & $/$ & $/$ & $/$ & - \\
$73-6$ & + & + & + & + & + & $/$ & $/$ & $/$ & - \\
$73-7$ & + & + & + & + & + & \pm & - & - & - \\
$73-8$ & + & + & + & + & + & $/$ & $/$ & $/$ & - \\
$73-9$ & + & + & + & + & + & $/$ & $/$ & $/$ & - \\
$73-10$ & + & + & + & + & + & $/$ & $/$ & $/$ & - \\
$73-11$ & + & $/$ & $/$ & $/$ & - & $/$ & $/$ & $/$ & - \\
$73-12$ & + & $/$ & $/$ & $/$ & - & $/$ & $/$ & $/$ & - \\
\hline
\end{tabular}

Note + : grown luxuriantly as on control medium,

$\pm:$ grown little or suppressed to grow,

- : killed,

I: not tested.

Table 3. The growth of Skeletonema costatum on media with various concentrations of 14 domestic oil-spill emulsifiers sampled in August 1974

\begin{tabular}{cccccccccc}
\hline \hline \multirow{2}{*}{$\begin{array}{c}\text { Sample } \\
\text { No. }\end{array}$} & \multicolumn{10}{c}{ Concentration (ppm) } \\
\cline { 2 - 9 } & 100 & 180 & 320 & 560 & 1,000 & 1,800 & 3,200 & 5,600 & 10,000 \\
\hline $74-1$ & + & + & \pm & - & - & - & - & - & - \\
$74-2$ & + & + & + & + & + & + & \pm & - & - \\
$74-3$ & + & + & \pm & - & - & - & - & - & - \\
$74-4$ & + & + & \pm & \pm & - & - & - & - & - \\
$74-5$ & + & + & - & - & - & - & - & - & - \\
$74-6$ & $-*$ & - & - & - & - & - & - & - & - \\
$74-7$ & + & + & + & + & + & + & \pm & \pm & - \\
$74-8$ & + & + & \pm & - & - & - & - & - & - \\
$74-9$ & + & + & + & + & \pm & - & - & - & - \\
$74-10$ & + & + & + & \pm & - & - & - & - & - \\
$74-11$ & + & + & + & + & + & + & + & + & + \\
$74-12$ & + & \pm & - & - & - & - & - & - & - \\
$74-13$ & + & \pm & - & - & - & - & - & - & - \\
$74-14$ & + & + & + & + & + & + & \pm & - & - \\
\hline
\end{tabular}

Note *: grown slightly for 4 days after inoculation, but killed later. See also the footnote under Table 2. 
Table 4. The growth of Skeletonema costatum on media with various concentrations of 4 foreign oil-spill emulsifiers sampled in August 1975

\begin{tabular}{cccccccc}
\hline \hline & \multicolumn{7}{c}{ Concentration (ppm) } \\
\cline { 2 - 7 } Sample No. & 56 & 100 & 180 & 320 & 560 & 1,000 & 1,800 \\
\hline $75-1$ & + & \pm & - & - & - & - & - \\
$75-2$ & + & + & + & + & + & + & - \\
$75-3$ & + & + & + & - & - & - & - \\
$75-4$ & + & + & + & + & \pm & - & - \\
\hline
\end{tabular}

Note See the footnote under Table 2.

Table 5. Composition of several oil-spill emulsifiers shown in Table 1

\begin{tabular}{|c|c|c|}
\hline Sample No. & Solvent & Surfactant \\
\hline $71-1$ & Petroleum hydrocarbon & $\begin{array}{l}\text { POE* alkyl aryl ether } \\
\text { POE alkyl ether }\end{array}$ \\
\hline $71-2$ & Petroleum hydrocarbon & $\begin{array}{l}\text { POE alkyl phenol ether } \\
\text { POE alkylamide ether }\end{array}$ \\
\hline $71-3$ & Petroleum hydrocarbon & $\begin{array}{l}\text { POE alkyl phenol ether } \\
\text { Alkyl benzene sulfonate }\end{array}$ \\
\hline $71-15$ & Kerosene ..............70\% & $\begin{array}{l}\text { POE alkyl phenol ether } \ldots . .27 \% \\
\text { PEG** fatty acid ester } \ldots \ldots .3 \%\end{array}$ \\
\hline $71-19$ & $\begin{array}{l}\text { Petroleum hydrocarbon } \ldots . . .70 \% \\
\text { (composed of } 100 \% \text { aromatics) }\end{array}$ & $\left.\begin{array}{l}\text { Higher alcohol ester.........10\% } \\
\text { Non-ionic surfactant } \\
\text { Anionic surfactant }\end{array}\right\} \ldots \ldots .20 \%$ \\
\hline $71-21$ & Kerosene .............. 75\% & $\begin{array}{l}\text { POE alkyl phenol ether } \ldots \ldots . \ldots 18 \% \\
\text { POE alkyl ether } \ldots \ldots \ldots \ldots .7 \%\end{array}$ \\
\hline $71-26$ & Water................. $80 \%$ & POE alkyl phenol ether . . . . 20\% \\
\hline $71-30$ & Petroleum hydrocarbon & $\begin{array}{l}\text { POE alkyl aryl ether } \\
\text { Alkanolamine fatty acid ester }\end{array}$ \\
\hline $71-31$ & Petroleum hydrocarbon & Amine-type non-ionic surfactant \\
\hline $71-36$ & Petroleum hydrocarbon & $\begin{array}{l}\text { POE alkyl phenol ether } \\
\text { PEG oleate } \\
\text { Sorbitan monooleate }\end{array}$ \\
\hline $71-37$ & Petroleum hydrocarbon & $\begin{array}{l}\text { Sorbitan fatty acid ester } \\
\text { Alkyl alkanolamide }\end{array}$ \\
\hline $71-39$ & Petroleum hydrocarbon & $\begin{array}{l}\text { POE alkyl phenol ether } \\
\text { PEG oleate }\end{array}$ \\
\hline $71-41$ & Petroleum hydrocarbon & $\begin{array}{l}\text { POE alkyl ether } \\
\text { Alkyl alkanolamide } \\
\text { POE alkyl aryl ether }\end{array}$ \\
\hline $71-43$ & Kerosene $\ldots \ldots \ldots \ldots \ldots \ldots 70 \%$ & $\begin{array}{l}\text { PEG fatty acid ester } \ldots \ldots \ldots 27 \% \\
\text { Sorbitan fatty acid ester..... } 3 \%\end{array}$ \\
\hline $71-46$ & Petroleum hydrocarbon . .....70\% & $\begin{array}{l}\text { Higher fatty acid ester } \ldots \ldots \ldots 10 \% \\
\text { PEG alkylate } \ldots \ldots \ldots \ldots \ldots 20 \%\end{array}$ \\
\hline $71-52$ & $n$-paraffin & PEG ( 7 mole) oleate \\
\hline
\end{tabular}

Note *: Polyoxyethylene, ** Polyethyleneglycol. 
1973 年 8 月の試料は, 低毒性化に移行するための中間的な製品であり, 改良された低毒性製品に当時在 庫中の旧処方の製品を混合して市販したものもあつたようである。1974 年 8 月括よび 1975 年 8 月の試料 では，ほぼ全製品が全面的に低毒性化されたとみなしらる。すなわち, 界面活性剤部においては, 脂肪酸,

ソルビタン，あるいはソルビタン脂肪酸エステルなどに，それぞれェチレンオキサイドやエチレングリコー

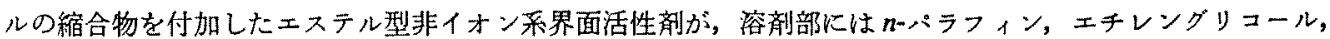
イソプロピルアルコール，ジェチレンダリコールモ/ブチルエーテル，水などが用いられて捛り，油処理剤 として，生分解性㧍よび対生物毒性のうえからこれ以上すぐれたものは考兄られないほどの組成に達してい る。

油処理剤の各成分の植物プランクトンならびに他の海洋生物への影響や蓄積性, 生分解性については，今 後の報文にゆずりたい。

格筆に際し，試料の入手にご尽力下さるとともに，有益な示唆を戴いた海上保安庁試験研究センター，お よび社団法人日本海難防止協会に深甚なる謝意を表す。

要約

1971 年 8 月に入手した国産扰よび外国産油処理剂 54 種類について， 3 種の海産植物プランクトン， なわち Chlamyd.sp., Nitz. closterium および Skel. costatum に対する致死濃度を, また 1973 年, 1974 年扰よび 1975 年の各 8 月に入手した国産 12 種類, 同 14 種類, 外国産 4 種類の油処理剤について, Skel. costatum に対する致死濃度を，それぞれ培養実験に上り求めた。

3 種のプランクトンでは，Skel. costatum がもつとも油処理郕に敏感で，Nitz. closterium がこれにつぎ， Chlamyd. sp. がもつとも耐性が強かつた。

油処理剂の対生物毒性は，その成分の改良の結果，年の経過とともに低書性化され，1974 年および 1975 年に入手した試料では，注とんどのものが Skel. costatumに対する致死濃度が $100 \mathrm{ppm}$ 以上で，なかには $10,000 \mathrm{ppm}$ でも生育可能な製品があつた。

\section{文献}

1) J. E. Smith: 'Torrey Canyon' Pollution and Marine Life, Cambridge Univ. Press, London, 1968, pp. 196.

2) J.D. Carthy and Don R. Arthur: The Biological Effects of Oil Pollution on Littoral Communities, Field Studies Council, London, 1968, pp. 198.

3) E. B. Cowell: The Ecological Effects of Oil Pollution on Littoral Communities, Inst. of Petroleum, London, 1971, pp. 250.

4) A. Nelson-Smith: in "Advances in Marine Biology" (ed. by F. S. Russell and M. Yonge), Vol. 8, Academic Press, London and New York, 1970, pp. 215-306.

5) A. Nelson-Smith: Oil Pollution and Marine Ecology, Elek Science, London, 1972, pp. 260.

6) 徳田 窝：化学と生物, 13, 93-95 (1975).

7) H. IWASAKI: Biol. Bull., 121, 173-187 (1961).

8) H. TOKUDA: in "Proc. VIII th International Seaweed Symp." (Bangor, 1974), in press. 